OPEN ACCESS

Edited by:

Bastian Schilling,

University Hospital Würzburg,

Germany

Reviewed by:

Tobias Bald,

The University of Queensland,

Australia

Frank Momburg,

German Cancer Research Center

(DKFZ), Germany

*Correspondence:

Dave Sprengers

d.sprengers@erasmusmc.n

Jaap Kwekkeboom

j.kwekkeboom@erasmusmc.nl

${ }^{\dagger}$ These authors share senior authorship

Specialty section:

This article was submitted to

Cancer Immunity and

Immunotherapy,

a section of the journal

Frontiers in Immunology

Received: 24 April 2021

Accepted: 09 July 2021

Published: 22 July 2021

Citation:

Ge Z, Peppelenbosch MP, Sprengers $D$ and Kwekkeboom J (2021) TIGIT, the Next Step Towards

Successful Combination Immune

Checkpoint Therapy in Cancer.

Front. Immunol. 12:699895.

doi: 10.3389/fimmu.2021.699895

\section{TIGIT, the Next Step Towards Successful Combination Immune Checkpoint Therapy in Cancer}

\author{
Zhouhong Ge, Maikel P. Peppelenbosch, Dave Sprengers ${ }^{*+}$ and Jaap Kwekkeboom ${ }^{\text {*t }}$ \\ Department of Gastroenterology and Hepatology, Erasmus University Medical Center (MC), Rotterdam, Netherlands
}

T cell immunoreceptor with Ig and ITIM domains (TIGIT) is an inhibitory receptor expressed on several types of lymphocytes. Efficacy of antibody blockade of TIGIT in cancer immunotherapy is currently widely being investigated in both pre-clinical and clinical studies. In multiple cancers TIGIT is expressed on tumor-infiltrating cytotoxic T cells, helper T cells, regulatory T cells and NK cells, and its main ligand CD155 is expressed on tumor-infiltrating myeloid cells and upregulated on cancer cells, which contributes to local suppression of immune-surveillance. While single TIGIT blockade has limited anti-tumor efficacy, pre-clinical studies indicate that co-blockade of TIGIT and PD-1/PD-L1 pathway leads to tumor rejection, notably even in anti-PD-1 resistant tumor models. Among inhibitory immune checkpoint molecules, a unique property of TIGIT blockade is that it enhances not only anti-tumor effector T-cell responses, but also NK-cell responses, and reduces the suppressive capacity of regulatory $T$ cells. Numerous clinical trials on TIGITblockade in cancer have recently been initiated, predominantly combination treatments. The first interim results show promise for combined TIGIT and PD-L1 co-blockade in solid cancer patients. In this review, we summarize the current knowledge and identify the gaps in our current understanding of TIGIT's roles in cancer immunity, and provide, based on these insights, recommendations for its positioning in cancer immunotherapy.

\section{Keywords: immunotherapy, T cells, NK cells, CD226, CD155}

\section{HIGHLIGHTS}

- TIGIT blockade synergizes with PD-1/PD-L1 blockade to enhance anti-tumor effects of $\mathrm{CD} 8^{+} \mathrm{T}$ cells.

- TIGIT blockade does not only reinvigorate anti-tumor $\mathrm{T}$ cell responses but also enhances antitumor NK cell responses.

- TIGIT blockade reduces the suppressive capacity of tumor-infiltrating regulatory T cells.

\footnotetext{
Abbreviations: TIGIT, T cell immunoglobulin and ITIM domain; ITIM, immunoreceptor tyrosine-based inhibitory motif; PD-1, Programmed cell Death protein 1; TIM3, T-cell immunoglobulin and mucin-domain containing-3; LAG3, Lymphocyteactivation gene 3; CTLs, Cytotoxic T lymphocytes; ICIs, immune checkpoint inhibitors; mAb, monoclonal antibody.
} 


\section{INTRODUCTION}

Therapeutic immune checkpoint inhibitors (ICIs) aimed to restore the functionality of tumor-specific T-cells to combat malignant tumors have been shown to be effective in many cancer types. Specifically, anti-PD-1/PD-L1 therapies have been approved by FDA for treating more than ten cancer entities, including melanoma, non-small cell lung carcinoma (NSCLC), advanced hepatocellular carcinoma (HCC) and all types of deficient mismatch repair(dMMR) tumors (1-3).

However, only a subset of patients with these types of cancer showed durable clinical responses $(4,5)$, and numerous other types of cancer, among which MMR-proficient CRC, are resistant to anti-PD-1/PD-L1 therapies $(6,7)$, suggesting that in these patients mechanisms are present that limit the effects of antiPD-1/PD-L1 antibodies. An immunosuppressive tumor microenvironment, a paucity of $\mathrm{T}$ cells in tumors (so called immunologically "cold" tumors) and low tumor-mutational burden have all been suggested to contribute to the observed suboptimal therapeutic effects of anti-PD-1/PD-L1 therapies (8). In addition, although the PD-1/PD-L1 axis plays a central role in regulating $\mathrm{T}$ cell functions, there are many other co-inhibitory receptor-ligand interactions that can restrain anti-tumor functions of $\mathrm{CD}^{+} \mathrm{T}$ cells in the tumor micro-environment, either directly or indirectly. These co-inhibitory receptors include $\mathrm{T}$ cell immunoglobulin mucin domain 3 (TIM3) (9), lymphocyte-activation gene 3 (LAG3) (10), cytotoxic Tlymphocyte associated protein 4 (CTLA-4) (11) and T cell immunoreceptor with Ig and ITIM domains (TIGIT) (12). Their ligands are expressed on cancer cells and/or immune cells in many tumors. These inhibitory receptor-ligand interactions collaborate to achieve fine tuning of T-cell functions throughout the different phases of T-cell activation, and can contribute to resistance of tumors against PD-1/ PD-L1 blockade.

In preclinical and subsequent clinical studies, it has been demonstrated that co-blockade of PD-1 and a second coinhibitory receptor is able to augment the antitumor immunity versus single PD-1 blockade. Indeed, blockade of both PD-1 and CTLA-4 showed improved clinical efficacy in patients with, amongst others, melanoma (13) and advanced non-small-cell lung cancer (14) and hepatocellular carcinoma (15). However, combine PD-1 and CTLA-4 blockade is hampered by a high frequency of severe immune-related systemic adverse effects (16), therefore other less toxic combinations are urgently needed. Theoretically, TIGIT-blockade may be an interesting alternative for CTLA-4 blockade, because TIGIT knockout mice do not develop autoimmunity $(17,18)$, while CTLA-4 knockout mice die within 2-3 weeks due to severe autoimmunity (19).

Here we review the current knowledge of the immunomodulatory activity of TIGIT in anti-cancer immunity and its potential as a target for cancer immune checkpoint therapy. We identify gaps in our current understanding of TIGIT's roles in cancer immunity that require further study and, based on current insights, we provide recommendations for its positioning in cancer immune checkpoint therapy.

\section{TIGIT STRUCTURE, EXPRESSION, AND LIGANDS}

TIGIT [also identified as WUCAM (20), VSTM3 (17)] is a coinhibitory molecule that was first identified in 2009 (21). Similar to LAG3 and TIM3, TIGIT belongs to the immunoglobulin superfamily (22). It consists of an extracellular immunoglobulin variable (IgV) domain, a type 1 transmembrane domain and a cytoplasmic tail with an immunoreceptor tyrosine-based inhibitory motif (ITIM) and an Ig tail-tyrosine (ITT)-like motif (21-24). TIGIT is exclusively expressed on lymphocytes, including $\mathrm{CD}^{+} \mathrm{T}$ cells, memory and regulatory $\mathrm{CD} 4^{+} \mathrm{T}$ cells, follicular $\mathrm{CD} 4^{+} \mathrm{T}$ cells and NK cells $(20-22)$.

TIGIT binds to at least two nectin family members, CD155 (PVR, Necl-5) and CD112 (PVRL2, Nectin-2), but with much higher affinity to CD155 (Kd=1-3 nM) than to CD112 (Kd unmeasurable) (21). TIGIT shares these ligands with two other receptors; CD226 (DNAM-1) and CD96 (TACTILE), which deliver co-stimulatory and co-inhibitory signals, respectively. TIGIT competes with the costimulatory receptor CD226 for binding to CD155, but TIGIT has a higher affinity for CD155 $(\mathrm{Kd}=1-3 \mathrm{nM})$ compared to $\mathrm{CD} 226(\mathrm{Kd}=119 \mathrm{nM})(21)$. A recent paper shows that TIGIT also binds to nectin- 4 and that nectin-4 interacts only with TIGIT, and not with CD226 and CD96 (25), but little is known about the functional role of TIGIT-nectin-4 interaction in anti-tumor immunity.

CD155 is expressed on monocytes, dendritic cells (DCs), fibroblasts and endothelial cells, both in healthy tissues and in tumors. Additionally, CD155 is over-expressed on cancer cells in human malignancies including colon cancer (26), lung adenocarcinoma (27), melanoma (28), pancreatic cancer (29), glioblastoma (30) and hepatocellular carcinoma (31). Apart from its normal function in establishing cell-cell adhesion $(32,33)$, it also functions as the receptor of polio virus (34). Expression of CD155 on tumor cells facilitates tumor cell growth and migration by tumor-intrinsic mechanisms (30) and its overexpression is correlated with tumor progression and unfavorable prognosis (27-29). However, loss of CD155 on tumor cells not only reduces tumor growth by tumor-intrinsic mechanisms, but also improves response to anti-PD-1 antibody therapy in mouse tumor models (35). In addition, high CD155 expression in tumors is associated with resistance to anti-PD-1 therapy in metastatic melanoma patients (36). Moreover, PVRL1 (CD111, nectin-1) promotes TIGIT-mediated T cell suppression by stabilizing CD155 on the surface of HCC tumor cells, and PVRL1 knockdown in tumor cells in an HCC mouse model resulted in reduced tumor growth in a $\mathrm{CD} 8^{+} \mathrm{T}$ cell-dependent manner (37). High expression of CD155 on tumor cells promotes dysfunctionality of tumor infiltrating $\mathrm{CD}^{+} \mathrm{T}$ cells by driving internalization and proteasomal degradation of the costimulatory receptor $\mathrm{CD} 226$ in $\mathrm{CD}^{+} \mathrm{T}$ cells in mouse and human tumors (38). These data show that CD155 expression in tumors has dual tumor-promoting effects, both tumorintrinsic and by inhibition of anti-tumor immunity.

CD112 is expressed by DCs and monocytes (39) and overexpressed in different types of cancers such as acute myeloid 
leukemia (40), multiple myeloma (41-43) and epithelial cancers $(44,45)$. CD112 has higher affinity for CD112R (PVRIG) than for TIGIT, and suppresses T cells mainly via binding to CD112R $(46,47)$ and not via TIGIT $(48)$. Therefore, it is reasonable to consider that modulation of $\mathrm{T}$ cell and $\mathrm{NK}$ cell functions via TIGIT is mainly by mediated by interaction with CD155.

\section{THE MECHANISMS OF TIGIT CO-INHIBITION}

While all co-inhibitory receptors have the ability to suppress $\mathrm{T}$ cell activation, they differ in potency, kinetics of expression and with respect to the cellular signaling pathways they alter. Whereas the co-inhibitory checkpoint CTLA-4 acts downstream of TCRinduced signaling by targeting downstream effectors of PI3K through activation of the serine/threonine phosphatase PP2A (49), TIGIT acts more upstream (50). TIGIT can inhibit $\mathrm{CD}^{+} \mathrm{T}$ cell proliferation and activation by directly acting on TCR expression itself as engagement of TIGIT induces a downregulation of the TCR- $\alpha$ chain and molecules that comprise the TCR complex (18). In addition, TIGIT can reduce TCR-induced p-ERK signaling in $\mathrm{CD}^{+} \mathrm{T}$ cells (50). Binding of TIGIT on NK cells to its ligand CD155 suppresses NK-cell mediated cytotoxicity and IFN- $\gamma$ production through signaling cascades generated by ITIM and ITT-like motifs in its cytoplasmic tail (2224). However, TIGIT exerts its functions not only by direct cellintrinsic inhibitory signaling, but like CTLA4 which blocks binding of its co-stimulatory counterpart CD28 to their shared ligands CD80 and CD86, also in an indirect way. TIGIT can compete for ligand binding with CD226 thereby reducing T-cell co-stimulation via CD226 (51). In addition, TIGIT can prevent co-stimulatory signaling via CD226 by blocking CD226 homodimerization (52). Finally, TIGIT can suppress T-cells indirectly by modulating functions of cells expressing its ligand CD155. TIGIT expressed on $\mathrm{CD}^{+} \mathrm{T}$ cells induces IL-10 and suppresses IL-12 production by DCs via CD155 ligation and thereby inhibits $\mathrm{CD}^{+}{ }^{+} \mathrm{T}$ cell proliferation and IFN- $\gamma$ production (21). The mechanisms of TIGIT co-inhibition of $\mathrm{T}$ cells are illustrated in Figure 1.

\section{TIGIT's ROLE IN ANTI-CANCER IMMUNITY}

TIGIT is expressed on human tumor-infiltrating $\mathrm{CD}^{+} \mathrm{T}$ cells, NK cells, Th and Treg cells in melanoma $(54,55)$, NSCLC (56, $57)$, colon cancer (52), HCC $(31,58)$, gastric cancer (59), glioblastoma (60) and hematological malignancies (42, 61, 62). Increased numbers of intra-tumoral $\mathrm{TIGIT}^{+} \mathrm{CD} 4^{+}$and $\mathrm{CD}^{+} \mathrm{T}$ cells are associated with inferior patient outcomes and poor survival in follicular lymphoma patients (61). High TIGIT expression on peripheral $\mathrm{CD}^{+} \mathrm{T}$ cells is associated with primary refractory disease in acute myelogenous leukemia (AML) patients (62). Circulating $\mathrm{PD}-1^{+} \mathrm{TIGIT}^{+} \mathrm{CD} 8^{+} \mathrm{T}$-cell populations are negatively correlated with overall survival rate

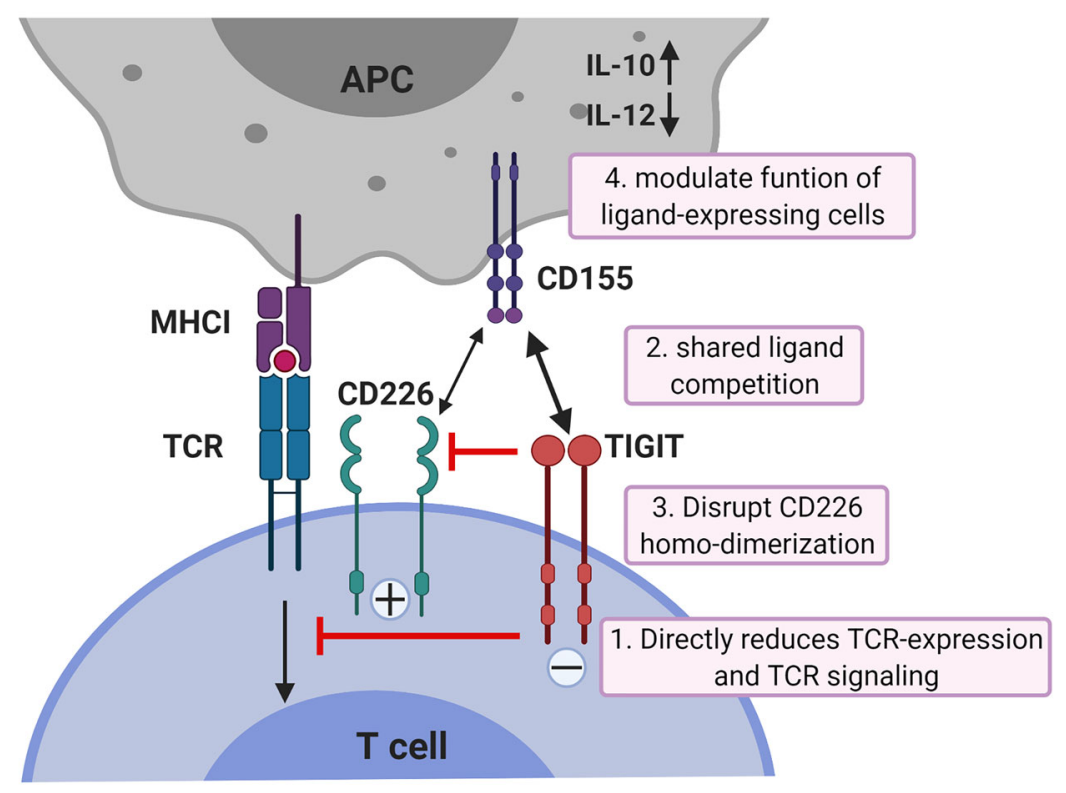

FIGURE 1 | Mechanisms of TIGIT inhibition in T cells. TIGIT displays multiple inhibitory mechanisms in T cells. 1) TIGIT binds to CD155 and delivers intracellular inhibitory signals which directly reduces TCR-expression and TCR signaling. 2) TIGIT binds to CD155 with much higher affinity than its co-stimulatory counterpart CD226 and thereby can replace CD226 from CD155 binding; 3) or disrupts CD226 homo-dimerization to inhibit CD226-mediated T cell activation. 4) TIGIT binds to CD155 on APCs to induce IL-10 production and decrease IL-12 production which indirectly inhibits T cells. APCs, antigen-presenting cells. The figure is adapted based upon the cartoon from Pauken KE et al. (53). 
and progression-free survival rates in patients with hepatitis $\mathrm{B}$ virus associated HCC (HBV-HCC) (63). These data suggest a suppressive role of TIGIT in anti-tumor immunity in cancer patients. In the next four paragraphs, we will discuss via which tumor-infiltrating immune cell populations TIGIT may inhibit anti-tumor immunity, and how such inhibition could be overcome.

\section{TIGIT Blockade Synergizes With PD-1 Blockade to Enhance Anti-Tumor Effects of Intra-Tumoral CD8 ${ }^{+}$T Cells}

Generating $\mathrm{CD}^{+} \mathrm{T}$ cell antitumor responses is the major goal of most cancer immunotherapies because it is considered that $\mathrm{CD}^{+} \mathrm{T}$ cells not only provide effective immediate cytotoxicity against tumor cells, but also generate immunological memory to sustain anti-tumor immunity. Knockdown of TIGIT was able to restore in vitro IFN- $\gamma$ and TNF- $\alpha$ production by circulating $\mathrm{CD}^{+} \mathrm{T}$ cells from AML patients (62). Nevertheless, single TIGIT blockade achieved no or moderate anti-tumor efficacy in experimental tumor models $(37,52,58,64)$ and in enhancing in vitro functionality of human tumor-infiltrating $\mathrm{CD} 8^{+} \mathrm{T}$ cells (31). However, since CD155-TIGIT interaction contributes to cancer resistance to PD-1 blockade $(35,36)$, inhibition of TIGIT may be a promising strategy to increase the efficacy of PD-1 blockade therapy, especially to combat PD-1 inhibitor resistant tumors (37).

TIGIT is coordinately expressed with PD-1 on human and murine CD8 ${ }^{+}$TILs $(52,54,58,65,66)$, whereas CD226 expression is negatively associated with PD-1 expression on CD8 ${ }^{+}$TILs (31, 54). In mouse tumors, TIGIT marks a dysfunctional subset of CD8 ${ }^{+}$TILs that co-expresses high levels of PD-1 and TIM3 (66, 67). Similarly, co-expression of TIGIT and PD-1 identifies dysfunctional $\mathrm{CD}^{+}$and $\mathrm{CD}^{+}$TIL subsets in human B-cell lymphoma (65). We recently showed that in HCC patients TIGIT expression is up-regulated whereas CD226 expression is down-regulated on $\mathrm{CD}^{+}$TILs that display high PD-1 expression. These TIGIT ${ }^{+} \mathrm{PD}-1^{\text {hi }} \mathrm{CD}^{+} \mathrm{T}$ cells co-express exhaustion markers TIM3 and LAG3, show functional defects in IFN- $\gamma$ and TNF- $\alpha$ production, and demonstrate higher TOX expression and lower TCF-1 expression compared to TIGIT $^{+} \mathrm{PD}-1^{\text {int }} \mathrm{CD}^{+}$TILs, together characterizing them as exhausted dysfunctional $\mathrm{CD} 8^{+}$ TILs (31). While CD ${ }^{+} \mathrm{PD}-1^{\text {int }} \mathrm{TIGIT}^{+} \mathrm{T}$ cells are found in tumors of all HCC patients, TIGIT-expressing $\mathrm{CD} 8^{+} \mathrm{PD}-1^{\text {hi }}$ TILs are present in a subset of HCC patients (31) and are associated with poor prognosis (68), supporting their poor anti-tumor functions. Interestingly, it has been demonstrated that in vitro PD-1 blockade upregulates TIGIT expression on NY-ESO-1reactive $\mathrm{CD}^{+} \mathrm{T}$ cells from melanoma patients (54), and that TIGIT is the most-upregulated immune checkpoint on $\mathrm{CD}^{+}$ TILs upon anti-PD-1 treatment in a PD-1 non-responsive HCC mouse model (37), suggesting TIGIT as a plausible target to improve efficacy of anti-PD-1 treatment.

In the MC38 colon carcinoma mouse model, TIGIT blockade alone led to a small but uniform retardation of tumor growth. Anti-PD-1 treatment alone resulted in a variable response with most mice showing initial tumor regression followed by escape and only one mouse showing complete tumor regression. However, anti-TIGIT/anti-PD-1 co-blockade increased IFN- $\gamma$, TNF- $\alpha$ and IL- 2 in CD8 ${ }^{+}$TILs and resulted in complete tumor regression in all mice (69). Likewise, in the CT26 colon carcinoma (52) and glioblastoma (64) mouse models, coblockade of TIGIT and PD-1/PD-L1 pathway synergistically decreased tumor burden and improved survival by increasing IFN $-\gamma^{+} \mathrm{CD}^{+}$TILs (52). In HCC-bearing mice which were resistant to $\mathrm{PD}-1$ blockade, dual blockade of TIGIT and PD-1 expanded the effector memory $\mathrm{CD}^{+} \mathrm{T}$ cell population and increased ratio of cytotoxic $\mathrm{T}$ cells to Treg in tumors, resulting in suppressed tumor growth and prolonged survival (37). Combined PD-1/TIGIT blockade resulted also in another mouse HCC model in synergistic inhibition of tumor growth and significantly prolonged mice survival (58). Furthermore, coblockade of PD-1 and TIGIT increased the in vitro proliferation, cytokine production and anti-tumor function of $\mathrm{CD}^{+}$TILs from HCC and melanoma patients $(31,54)$.

The balance of TIGIT/CD226 expression on $\mathrm{CD}^{+}{ }^{+} \mathrm{T}$ cells is important for proper $\mathrm{CD}^{+}$function, and the effect of TIGIT blockade is abrogated by CD226-blockade (31, 52, 70, 71), demonstrating that co-stimulation via CD226 is required for stimulatory effect of TIGIT blockade on $\mathrm{CD} 8^{+} \mathrm{T}$ cells. CD $226^{\text {hi }}$ $\mathrm{CD} 8^{+} \mathrm{T}$ cells but not $\mathrm{CD} 226^{\mathrm{lo}} \mathrm{CD} 8^{+} \mathrm{T}$ cells are required for antiTIGIT responses (71). Remarkably, CD226 is also required for enhancement of anti-tumor $\mathrm{CD}^{+} \mathrm{T}$-cells responses by PD-1 blockade. Anti-PD-1 cancer treatment efficacy is hampered in $\mathrm{CD} 226^{-1-}$ mice $(38,72)$. Moreover, numbers of $\mathrm{CD} 226^{+} \mathrm{CD} 8^{+}$ TILs in pre-treatment tumor biopsies of melanoma patients are associated with improved progression-free survival following single anti-PD-1 therapy or anti-PD-1/anti-CTLA4 coblockade (38). Unfortunately, CD226 expression is downregulated on $\mathrm{CD}^{+}$TILs in mouse and human tumors $(38,54$, 71,72 ), especially on $\mathrm{CD} 8^{+} \mathrm{PD}-1^{\text {hi }}$ exhausted dysfunctional $\mathrm{CD} 8^{+}$ TILs (31) which have been shown to contain the majority of tumor-reactive cells $(57,73)$. As mentioned above, downregulation of $\mathrm{CD} 226$ on $\mathrm{CD}^{+} \mathrm{T}$ cells in tumors is driven by its engagement with CD155 which causes internalization and proteasomal degradation of CD226 (38) but additionally, PD-1 signaling suppresses CD226 signaling (70). These mechanisms may explain the limited effect of single TIGIT blockade on $\mathrm{CD}^{+}$ TIL anti-tumor functions. Interestingly, blockade of PD-1 restores CD226 co-stimulatory signaling (70), and this observation may explain the synergy between PD-1 and TIGIT blockade in enhancing $\mathrm{CD}^{+}$TIL responses.

Together with pre-clinical $(35,37,38)$ and clinical data (36) showing that CD155 expression on tumor cells contributes critically to resistance to anti-PD-1 immunotherapy, the preclinical data that demonstrate and mechanistically explain synergy between TIGIT-blockade and PD-1 blockade to enhance anti-tumor $\mathrm{CD}^{+} \mathrm{T}$ cell immunity, argue that dual PD1 and TIGIT blockade is a promising combinatorial approach to overcome resistance to $\mathrm{PD}-1 / \mathrm{PD}-\mathrm{L} 1$ single blockade. The interactions between the mechanisms of $\mathrm{T}$ cell co-inhibition by TIGIT and PD-1 interactions are depicted in Figure 2. 

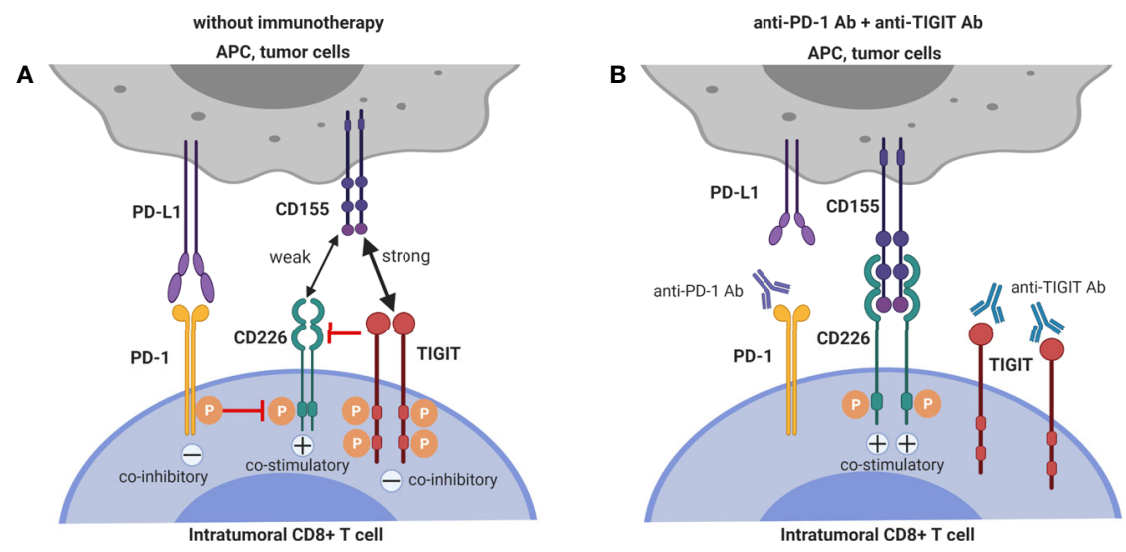

FIGURE 2 | Dual blockade of TIGIT and PD-1 has synergistic effects on intra-tumoral CD8+ T cells. (A) CD226 co-stimulatory signaling is suppressed by both TIGIT and PD-1 signaling. (B) Co-blockade of PD-1 and TIGIT synergizes to restore CD226 co-stimulatory signaling.

\section{Blockade of TIGIT on Tregs Reduces Their Immunosuppressive Functions}

Tregs play a dominant role in the regulation of antitumor immunity, and suppress multiple steps of the cancer immunity cycle. In contrast to the dampening action that TIGIT ligation has on $\mathrm{CD} 8^{+} \mathrm{T}$ - and $\mathrm{NK}$ cell functions, the suppressive function of Treg is enhanced by engagement of TIGIT on Treg. TIGIT is constitutively expressed in most Tregs in humans $(31,74-76)$ and mice (74), and agonistic TIGIT ligation augments the suppressive function and stability of these cells $(74,76)$. Conversely, agonistic ligation of CD226 on Tregs disrupts their suppression (76). High TIGIT expression marks highly active suppressive Tregs. Compared to TIGIT ${ }^{-}$Tregs, TIGIT $^{+}$Tregs express higher levels of FoxP3, co-inhibitory molecules (ICOS,
CTLA4, PD-1 and TIM3) as well as the immunosuppressive cytokine IL-10, indicating that TIGIT $^{+}$Treg might be optimally equipped for mediating immunosuppression $(67,74,76)$. TIGIT $^{+}$Treg specifically suppress pro-inflammatory $\mathrm{T}$ helper 1 (Th1) and Th17 cells, but not Th2 cell responses, and ligation of TIGIT on Treg induces production of fibrinogen-like protein 2 which suppresses effector T cell proliferation (74). Additionally, TIGIT signaling in Tregs upregulates CCR8 which may promote Treg migration and retention in tumor tissue $(67,77$, 78) (Figure 3A).

TIGIT $^{+}$Treg have been demonstrated to accumulate both in mouse tumors (67) and in several types of human tumors (76, 79). In HCC TILs, Treg represent the population of lymphocytes with highest TIGIT expression (31). In contrast, CD226 is down-
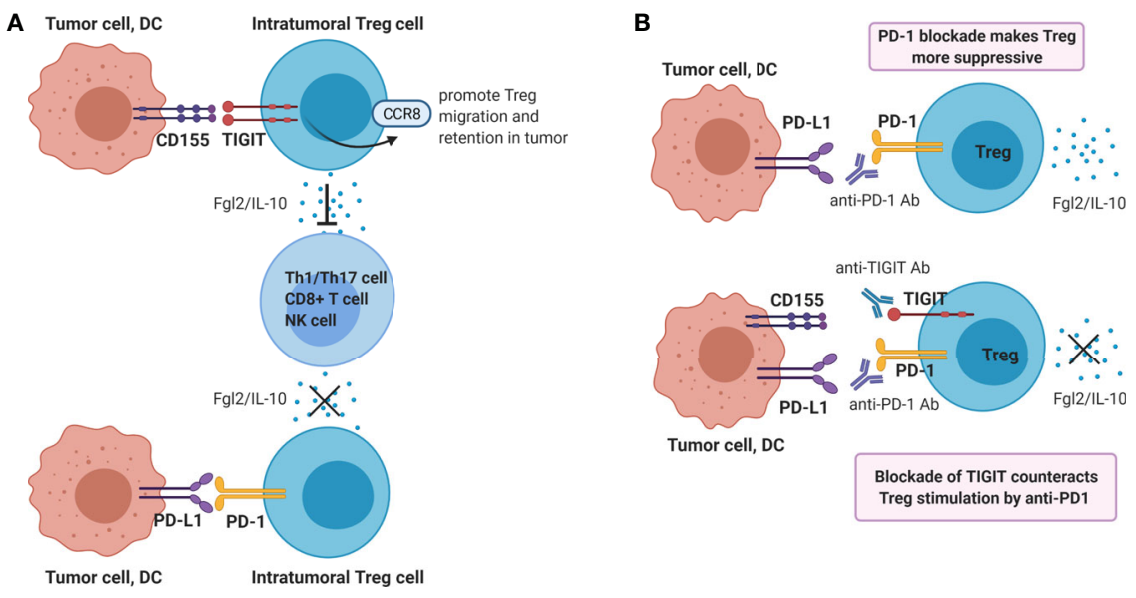

Blockade of TIGIT counteracts Treg stimulation by anti-PD1

FIGURE 3 | Ligation of TIGIT on Tregs contributes to dampening of anti-tumor immunity. (A) Ligation of TIGIT augments suppressive function of Tregs, which inhibits Th1/17 cell, CD8 ${ }^{+} \mathrm{T}$ cell or NK responses via production of Fgl2 and IL-10. On the contrary, PD-1 ligation may reduce Treg suppressive function. (B) Single blockade of PD-1 may enhance Treg immunosuppression, whereas dual blockade of TIGIT and PD-1 may counteract this resistance mechanism. 
regulated on tumor-infiltrating Treg, and a high TIGIT/CD226 expression ratio on tumor-infiltrating Tregs correlates with high Treg frequencies in tumors and poor clinical outcome in melanoma patients treated with anti-PD-1 and/or anti-CTLA4 immune checkpoint blockade, suggesting that the TIGIT/CD226 ratio in Tregs is a marker of Treg stability (76). In an in vitro study, TIGIT blockade depleted FoxP3 ${ }^{+}$Tregs while increasing proliferation of IFN $\gamma$-producing $\mathrm{CD}^{+} \mathrm{T}$ cells from peripheral blood from patients with multiple myeloma (42). Adoptive transfer experiments in mouse tumor models have even suggested that TIGIT ligation dampens anti-tumor immunity predominantly via regulatory $\mathrm{T}$ cells, rather than through a direct effect on TIGIT $^{+} \mathrm{CD}^{+} \mathrm{T}$ cells (67). However, a study in which different $\mathrm{T}$-cell subsets were depleted by specific antibodies found that $\mathrm{CD}^{+} \mathrm{T}$ cell depletion as well as Treg depletion could abrogate the anti-tumor effects of TIGITblockade in a mouse cancer model (66).

Whether PD-1-blockade might synergize with TIGITblockade in reducing suppression of intra-tumoral immunity Treg has not yet been investigated. The functional effects of PD-1 expression on Tregs is still a matter of debate. On the one hand, PD-1-deficient mouse Tregs have an enhanced suppressive capacity (80) and in vitro PD-L1 blockade augmented the suppressive capacity of Treg from HCV-infected patients (81). Moreover, PD-1 blockade enhanced the suppressive function PD- $1^{+}$Treg isolated from human tumors (82). On the other hand, interaction between $\mathrm{PD}-1$ on Tregs from mice with chronic LMCV-infection with PD-L1 expressed on $\mathrm{CD}^{+} \mathrm{T}$ cells was found to contribute to their capacity to suppress $\mathrm{CD}^{+} \mathrm{T}$ cell functions (83) and blockade of PD-L1 has been shown to reduce the in vitro suppressive function of human tumor-infiltrating Treg (79).

Therefore, PD-1/PD-L1 blockade may either enhance or reduce the suppressive capacity of $\mathrm{PD}$-1-expressing Treg in the tumor micro-environment. In both cases, co-blockade of TIGIT may be beneficial. If PD-1/PD-L1 blockade enhances intratumoral Treg immunosuppression, this mechanism may serve as a resistance mechanism against $\mathrm{PD}-1 / \mathrm{PD}-\mathrm{L} 1$ blockade, which is supported by recent data in cancer patients treated with antiPD-1 antibody (82). In this case, co-treatment with a blocking anti-TIGIT antibody may counteract this resistance mechanism (Figure 3B). Alternatively, if PD-1 and TIGIT expressed on chronically activated Treg present within the tumor microenvironment both contribute to their strong suppressive capacity, PD-1 blockade may synergize with TIGIT-blockade in reducing local immune-suppression exerted by tumorinfiltrating Treg functions. Both mechanisms may contribute to the synergistic effect of dual TIGIT/PD-1 blockade on antitumor immunity observed in pre-clinical models, and both hypotheses are worth to be investigated.

\section{The Role of TIGIT in Regulation Of Memory CD4 ${ }^{+} \mathrm{T}$ Cells in Cancer Is Under-Investigated}

The requirement for $\mathrm{CD} 4^{+} \mathrm{T}$ cells in anti-tumor responses has been attributed to providing help during priming to achieve full activation and effector function of tumor-specific $\mathrm{CD}^{+} \mathrm{T}$ cells (84). Mouse TIGIT $^{-/-} \mathrm{CD}^{+} \mathrm{T}$ cells showed increased proliferation upon re-stimulation with antigenic peptide, and produced higher amounts of IFN- $\gamma$ and lower amounts of IL-10, indicating a $\mathrm{T}$ cell intrinsic opposite effect in regulating IFN- $\gamma$ versus IL-10 production in $\mathrm{CD}^{+} \mathrm{T}$ cells (18). Moreover, the interaction of TIGIT on mouse Th with CD155 on DCs induced phosphorylation of CD155 and consequently upregulation of IL-10 production and downregulation of IL-12 production by DC, which suggests the existence of an IL-10-driven feedback loop for TIGIT-mediated Th cell suppression (21). TIGIT is expressed on around $20 \%$ of intra-tumoral Th in HCC patients, but not over-expressed compared to Th in tumor-free liver tissue and in the circulation (31). Similar to $\mathrm{CD}^{+} \mathrm{T}$ cells and Treg, CD226 is downregulated on intra-tumoral Th in HCC patients. In contrast, TIGIT is highly expressed on effector memory (around 80\%), effector (around 50\%) and central memory (around $40 \%$ ) $\mathrm{CD}^{+} \mathrm{T}$ cells in follicular lymphoma patients (50). PD- $1^{+} \mathrm{TIGIT}^{+} \mathrm{CD}^{+} \mathrm{T}$ cells from non-Hodgkin lymphoma patients produced lower amounts of IL2, IFN- $\gamma$ and TNF- $\alpha$ compared to other subsets after re-stimulation (65), suggesting loss of poly-functionality. Indeed, tumor-infiltrating $\mathrm{CD} 4^{+}$ $\mathrm{T}$ cells expressing IL2 were increased after TIGIT blocking monoclonal antibody $(\mathrm{mAb})$ treatment in a head and neck squamous cell carcinoma mouse model (66). Moreover, animals treated with dual anti-TIGIT/PD-1 antibodies showed increased IFN- $\gamma$ secretion by $\mathrm{CD}^{+}$TILs in the MC38 colon tumor mouse model, compared to single anti-PD-1 treatment (69). There are few studies which investigated TIGIT function in regulation of $\mathrm{T}$ helper cells in tumors, and this requires further investigation.

\section{Blockade of TIGIT on NK Cells Augments Anti-Tumor Immunity}

NK cells not only detect and identify malignant cancer cells, but they also induce cancer cell death $(85,86)$, e.g. by destroying MHC class I-deficient tumor cells which are refractory to $\mathrm{CD}^{+} \mathrm{T}$ cell-mediated immunity. In contrast, lack of MHC class I expression renders cells vulnerable to NK cell killing, because they are devoid of a major NK-cell inhibitory mechanism exerted by binding of self-MHC class I to inhibitory Killer Immunoglobulin Receptors (KIR) and NKG2A/CD94. Interestingly, defects in MHC class I presentation are relatively frequent in cancer cells. Moreover, mutations in $\beta 2$ microglobulin which cause lack of surface MHC class I expression are also involved in acquired resistance to anti-PD-1 therapy $(87,88)$. For these tumors, appropriate activation of NK cells in the tumor microenvironment may be a promising alternative therapeutic option (89). In addition, NK cells help to trigger a more robust anti-tumor $\mathrm{T}$-cell response by engaging other immune cells $(90,91)$. For example, $\mathrm{CD}^{+} \mathrm{T}$ cell responses against tumor cells are stimulated by NK-initiated cytokine production (91-93).

TIGIT expression on tumor-infiltrating NK cells is associated with tumor progression and is linked to functional exhaustion of NK cells in multiple cancer models (94). NK cell functions are 
regulated by the net balance of signals perceived by their activating and inhibiting receptors (95). The CD226 activating receptor and the TIGIT and CD96 inhibitory receptors have been shown to be key regulators of anti-tumor immune responses by NK cells. They share the same ligand CD155 (96). In this review, we will focus on the role of TIGIT in regulating anti-tumor functions of NK cells. In the B16 melanoma mouse model, NK cell-specific TIGIT-deficiency led to improved survival. Additionally, it induced a lower frequency of tumor-infiltrating $\mathrm{CD}^{+} \mathrm{T}$ cells expressing TIGIT and TIM3, which suggested that NK cells expressing TIGIT might also indirectly contribute to the exhaustion of $\mathrm{CD}^{+} \mathrm{T}$ cells (94). Blockade of TIGIT inhibited tumor growth and prevented exhaustion of tumor-infiltrating NK cells in the CT26 colon carcinoma mouse model (94). Mechanistically, tumor cells expressing CD155 impair NK cell functions by downregulating their CD226 expression (97, 98). CD155-/- mice displayed reduced tumor growth and metastasis via CD226 upregulation and enhanced effector functions of NK cells (35). Similarly, NK cell-specific TIGIT-deficiency resulted in a greater frequency of intra-tumoral NK cells expressing CD226 in the B16 melanoma mouse model (94). Furthermore, antibody blockade of nectin-4 suppresses human tumor growth in SCID mice transplanted with human NK cells, while nectin-4 overexpression in human tumor cells led to increased tumor growth in the presence of human NK cells (25). However, whether TIGIT blockade synergizes with PD-1 blockade to improve NK cell cytotoxicity is as yet unknown. Notably, IL-15 can increase the expression of both CD226 and TIGIT by intra-tumoral NK cells (98), and combination therapy of IL-15 and TIGIT blockade increased cytotoxicity of NK cells against melanoma and suppressed lung metastasis in mouse melanoma models. The authors suggest the development of novel combinatorial immunotherapy with IL-15 and TIGIT blockade to promote NK cell-mediated destruction of MHC class I-deficient melanoma, which are refractory to $\mathrm{CD} 8^{+}$ T cell-mediated immunity (98).

In humans TIGIT was shown to have variable expression on NK cells, and high TIGIT expression correlated with reduced NK cell functions (99). A TIGIT/CD226 dysbalance with high TIGIT and low CD226 expression on intra-tumoral NK cells been shown in multiple human tumors, e.g. colorectal cancer (CRC) (98), ovarian cancer (100) and HCC (101), and compromises intra-tumoral NK cell functions. In vitro blockade of the TIGIT pathway significantly increased functions of circulating NK-cells, particularly in NK cells with high levels of TIGIT expression (99). TIGIT $^{+}$NK cells from metastatic melanoma patients displayed a lower cytolytic activity than TIGIT $^{-}$NK cells against $\mathrm{CD}_{155^{+}}$MHC class I-deficient melanoma cells (98). TIGIT blockade boosts in vitro functional responsiveness of ovarian cancer ascites-derived CD56 ${ }^{\mathrm{dim}} \mathrm{NK}$ cells in patients with baseline reactivity against ovarian cancer tumor cells (100). Blocking TIGIT was shown to increase circulating NK cell cytotoxicity against HCC cell lines, suggesting that targeting TIGIT may be a beneficial approach to improve NK cell function in HCC patients (101). Gur C et al. showed that a CRCassociated bacterium (Fusobacterium nucleatum) inhibits human NK cells via TIGIT, which can be blocked by antiTIGIT antibody (102), suggesting that NK-cell responses in CRC can be suppressed by the gut microbiome in a TIGITmediated fashion. Collectively, TIGIT blockade has convincingly been shown to enhance anti-tumor NK cell responses. The interaction of TIGIT on NK cells with its ligands and the effect of anti-TIGIT and IL-15 co-treatment on NK cells are illustrated in Figure 4.
A

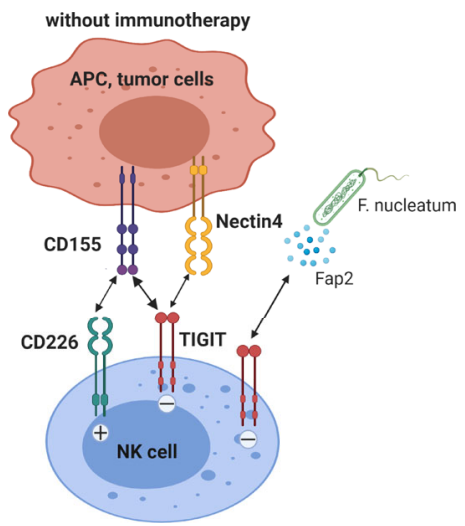

B

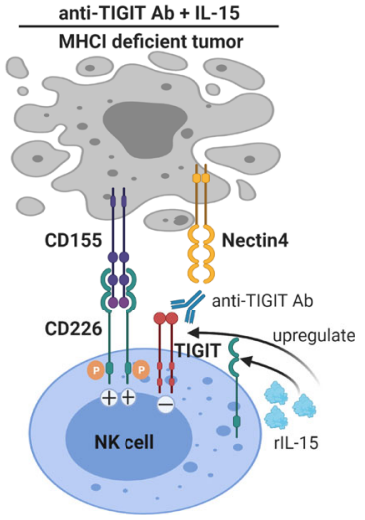

FIGURE 4 | Blockade of TIGIT on NK cells augments anti-tumor immunity. (A) NK cells expressing TIGIT are functionally impaired by binding to CD155 and nectin-4, and in colorectal cancer to Fap2 protein produced by a gut bacterium. (B) TIGIT blockade not only interrupts inhibitory signaling by TIGIT in NK cells, but also allows interaction of the co-stimulatory receptor CD226 with CD155. IL-15 treatment increases TIGIT and CD226 expression on NK cells. Thus IL-15 combined with TIGIT blockade further enhanced NK cells anti-tumor functions, especially promoting NK cell-mediated destruction of MHC class I-deficient tumors. 


\begin{tabular}{|c|c|c|c|c|c|c|}
\hline Agent & Trial sponsor & $\begin{array}{l}\text { ClinicalTrials.gov } \\
\text { identifier }\end{array}$ & Type of trial & $\begin{array}{l}\text { Estimated } \\
\text { enrollment }\end{array}$ & Tumor type & Combined therapy \\
\hline \multirow[t]{4}{*}{ BMS-986207 } & Bristol-Myers Squibb & NCT02913313 & Phase $1 / 2$ & 170 & Advanced solid tumors & $\begin{array}{l}\text { Monotherapy or combined with nivolumab } \\
\text { (anti-PD-1 mAb) }\end{array}$ \\
\hline & $\begin{array}{l}\text { Multiple Myeloma Research } \\
\text { Consortium }\end{array}$ & NCT04150965 & Phase 1/2 & 104 & Refractory multiple myeloma & $\begin{array}{l}\text { Monotherapy or combined with pomalidomide and } \\
\text { dexamethasone }\end{array}$ \\
\hline & Compugen Ltd & NCT04570839 & Phase 1/2 & 100 & Advanced solid tumors & $\begin{array}{l}\text { Combined with Nivo and COM701(inhibitor of poliovirus } \\
\text { receptor) }\end{array}$ \\
\hline & Genentech/Roche & NCT03563716 & Phase 2 & 135 & $\begin{array}{l}\text { Locally advanced or metastatic Non-small cell } \\
\text { lung cancer (NSCLC) }\end{array}$ & Combined with atezolizumab (anti-PD-L1 mAb) \\
\hline \multirow[t]{16}{*}{$\begin{array}{l}\text { Tiragolumab } \\
\text { (MTIG7192A; RG6058) }\end{array}$} & Roche & NCT04294810 & Phase 3 & 500 & $\begin{array}{l}\text { Locally advanced or metastatic } \\
\text { PD-L1-selected NSCLC }\end{array}$ & Combined with atezolizumab \\
\hline & & NCT04513925 & Phase 3 & 800 & NSCLC stage III & $\begin{array}{l}\text { Combined with atezolizumab compared with } \\
\text { Durvalumab }\end{array}$ \\
\hline & & NCT04619797 & Phase 2 & 200 & Unresectable or metastatic NSCLC & Combined with atezolizumab and pemetrexed \\
\hline & & NCT04256421 & Phase 3 & 400 & $\begin{array}{l}\text { Untreated extensive-stage small cell lung } \\
\text { cancer (SCLC) }\end{array}$ & $\begin{array}{l}\text { Combined with atezolizumab and carboplatin and } \\
\text { etoposide (CE) }\end{array}$ \\
\hline & & NCT04308785 & Phase 2 & 363 & SCLC & Combined with atezolizumab VS atezolizumab \\
\hline & & NCT03281369 & Phase 1b/2 & 410 & Esophageal cancer & $\begin{array}{l}\text { Combined with atezolizumab VS atezolizumab and } \\
\text { chemotheraoy }\end{array}$ \\
\hline & & NCT04540211 & Phase 3 & 450 & Unresectable esophageal cancer & $\begin{array}{l}\text { Combined with atezolizumab +paclitaxel and cisplatin } \\
\text { (PC) VS placebo+PC }\end{array}$ \\
\hline & & NCT04543617 & Phase 3 & 750 & $\begin{array}{l}\text { Unresectable esophageal squamous cell } \\
\text { carcinoma }\end{array}$ & Combined with atezolizumab VS atezolizumab \\
\hline & & NCT04524871 & Phase 1/2 & 100 & Advanced liver cancers & Combined with Atezolizumab + Bevacizumab \\
\hline & & NCT04584112 & Phase 1 & 80 & Triple-negative breast cancer & Combined with atezolizumab + chemotherapy \\
\hline & & NCT04045028 & Phase 1 & 52 & Refractory multiple myeloma & Monotherapy or combined with daratumumab or rituximab \\
\hline & & NCT02794571 & Phase 1 & 540 & Locally advanced or metastatic tumors & $\begin{array}{l}\text { Monotherapy or in combined with atezolizumab and/or } \\
\text { other anti-cancer therapies }\end{array}$ \\
\hline & & NCT04300647 & Phase 2 & 220 & Cervical cancer (PD-L1-positive) & Combined with atezolizumab \\
\hline & & NCT03281369 & Phase $1 / 2$ & 410 & Gastric and esophageal cancer & Combined with atezolizumab with/without cisplatin $+5 \mathrm{FU}$ \\
\hline & & NCT03193190 & Phase 1/2 & 290 & Metastatic pancreatic ductal Adenocarcinoma & Combined with atezolizumab +chemotherapy \\
\hline & & NCT03869190 & Phase 1/2 & 385 & $\begin{array}{l}\text { Locally advanced or metastatic urothelial } \\
\text { carcinoma }\end{array}$ & Combined with atezolizumab \\
\hline \multirow[t]{2}{*}{$\begin{array}{l}\text { Tiragolumab } \\
\text { (MTIG7192A; RG6058) }\end{array}$} & Roche & NCT04665843 & Phase 2 & 120 & $\begin{array}{l}\text { PD-L1-positive squamous cell carcinoma of } \\
\text { the head and neck }\end{array}$ & Combined with atezolizumab \\
\hline & & NCT03708224 & Phase 2 & 55 & $\begin{array}{l}\text { Squamous cell carcinoma of the head and } \\
\text { neck }\end{array}$ & Combined with atezolizumab VS atezolizumab \\
\hline \multirow[t]{8}{*}{ MK-7684 } & Merck & NCT02964013 & Phase 1 & 492 & Advanced solid tumors & $\begin{array}{l}\text { Monotherapy or combined with pembrolizumab (anti- } \\
\text { PD-1 mAb) }\end{array}$ \\
\hline & & NCT04305041 & Phase $1 / 2$ & 200 & Melanoma & Combined with pembrolizumab VS pembrolizumab \\
\hline & & NCT04305054 & Phase $1 / 2$ & 135 & Melanoma & Combined with pembrolizumab VS pembrolizumab \\
\hline & & NCT04738487 & Phase 3 & 598 & PD-L1 positive metastatic NSCLC & Combined with pembrolizumab VS pembrolizumab \\
\hline & & NCT04725188 & Phase 2 & 240 & Metastatic NSCLC & $\begin{array}{l}\text { Combined with pembrolizumab +Docetaxel VS } \\
\text { Docetaxel }\end{array}$ \\
\hline & & NCT04165070 & Phase 2 & 90 & Advanced NSCLC & $\begin{array}{l}\text { Combined with pembrolizumab + Carboplatin + } \\
\text { Paclitaxel }\end{array}$ \\
\hline & & NCT02861573 & Phase 1 & 1000 & Metastatic castrate resistant prostate cancer & Combined with pembrolizumab \\
\hline & & NCT04303169 & Phase $1 / 2$ & 65 & Stage III melanoma & Combined with pembrolizumab VS pembrolizumab \\
\hline
\end{tabular}




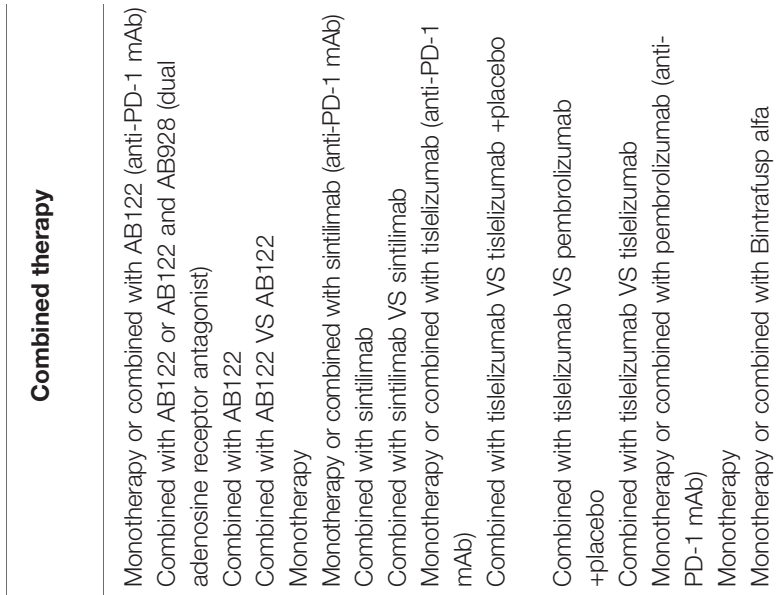
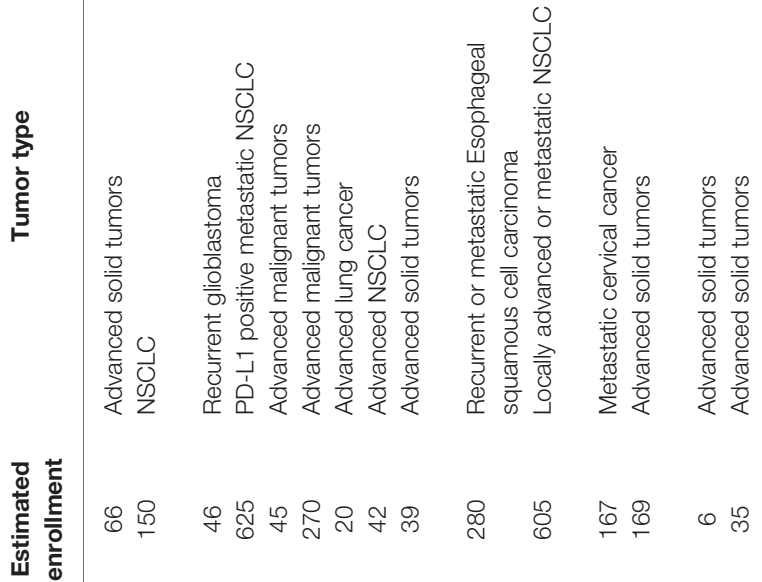

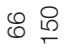

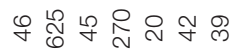

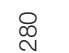

ชิ

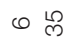

to

$\stackrel{2}{\vDash}$

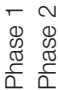
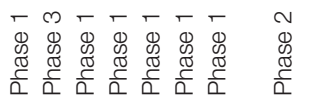

\begin{tabular}{l}
$m$ \\
0 \\
0 \\
$\mathbb{0}$ \\
$\frac{1}{0}$ \\
\hline 1
\end{tabular}

$\begin{array}{ll}\sim & - \\ 0 & 0 \\ \infty & 8 \\ 0 & 0 \\ \frac{0}{0} & \frac{1}{0} \\ \frac{0}{2}\end{array}$

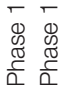

ว
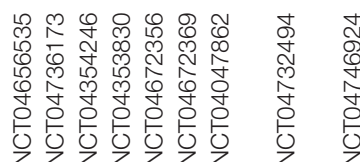

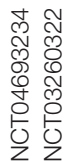
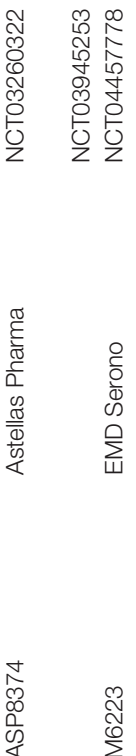

\section{TIGIT IN CLINICAL TRIALS TO TREAT CANCER}

Over last two years, the above mentioned immunomodulatory effects of TIGIT have attracted the attention from pharmaceutical companies worldwide. Currently, nine human anti-TIGIT mAbs are being tested in 43 phase $1 / 2 / 3$ clinical trials either as a monotherapy or, in most studies, in combination with anti-PD1/PD-L1 antibodies or chemotherapies for the treatment of advanced solid tumors, and in two trials in multiple myeloma (Table 1). Recently, in a phase I study anti-TIGIT antibody vibostolimab was demonstrated to be well tolerated as monotherapy and in combination with pembrolizumab (antiPD-1 antibody), achieving antitumor activity in patients with advanced NSCLC naïve or refractory to anti-PD-1/PD-L1 therapy (NCT02964013) $(103,104)$. The first data of the clinical efficacy of TIGIT mAbs have been reported as well. Interim data from an ongoing global phase II trial (CITYSCAPE, NCT03563716) demonstrated the improved efficacy of an anti-TIGIT antibody tiragolumab in combination with anti-PD-L1 antibody atezolizumab compared to atezolizumab alone in PD-L1positive metastatic NSCLC patients in terms of overall response and progression free survival (105). Importantly, all grade 3-5 adverse events (AEs) were similar in both groups (48\% vs 44\%) (105), in accordance with pre-clinical data showing limited immunotoxicity in TIGIT-deficiency in mice, as discussed earlier.

\section{CONCLUDING REMARKS}

Therapeutic immune checkpoint inhibition has revolutionized cancer treatment, and recent experience has made clear that combination therapies that target multiple CPI are more effective than monotherapies. TIGIT has been shown to be expressed by dysfunctional $\mathrm{CD}^{+}{ }^{+} \mathrm{T}$ cells and NK cells, as well as highly immunosuppressive regulatory $\mathrm{T}$ cells in mouse and human tumors. Its main ligand CD155 is over-expressed in several types of cancer and hampers immune surveillance by interacting with TIGIT on these immune cells. Preclinical studies have demonstrated that blocking TIGIT-signaling improves $\mathrm{CD} 8^{+}$ $\mathrm{T}$-cell and NK-cell responses and reduces suppressive functions of regulatory $\mathrm{T}$ cells. However, single TIGITblockade has minimal effects on tumor growth in most experimental tumor models, and is also insufficient to reinvigorate functions of human tumor-infiltrating $\mathrm{CD}^{+} \mathrm{T}$ cells. TIGIT-blockade synergizes with PD-1/PDL-1 blockade to enhance anti-tumor $\mathrm{CD}^{+} \mathrm{T}$-cell immunity in pre-clinical models, and is even effective in mouse tumors models that are resistant of PD-1 blockade, thus providing hope for clinical efficacy in patients with anti-PD-1 resistant tumors. A unique property of TIGIT among inhibitory immune checkpoints is that its blockade not only augments anti-tumor effector $\mathrm{CD}^{+} \mathrm{T}$-cell responses, but also anti-tumor NK-cell responses, and reduces the suppressive capacity of regulatory $\mathrm{T}$ cells. Whether TIGIT blockade can enhance T-helper cell responses it largely unknown. The clinical proof of its efficacy, especially for 
cancers that are resistant against single anti-PD-1 therapy, in ongoing clinical trials is eagerly awaited for.

\section{AUTHOR CONTRIBUTIONS}

ZG wrote the initial draft of the manuscript and made figures. MP contributed to outline and revision of the manuscript. DS and JK contributed to writing and revision of the manuscript. All authors contributed to the article and approved the submitted version.

\section{REFERENCES}

1. Twomey JD, Zhang B. Cancer Immunotherapy Update: FDA-Approved Checkpoint Inhibitors and Companion Diagnostics. AAPS J (2021) 23(2):39. doi: 10.1208/s12248-021-00574-0

2. Sanmamed MF, Chen L. A Paradigm Shift in Cancer Immunotherapy: From Enhancement to Normalization. Cell (2018) 175:313-26. doi: 10.1016/ j.cell.2018.09.035

3. Le DT, Durham JN, Smith KN, Wang H, Bartlett BR, Aulakh LK, et al. Mismatch Repair Deficiency Predicts Response of Solid Tumors to PD-1 Blockade. Science (2017) 357:409-13. doi: 10.1126/science.aan6733

4. El-Khoueiry AB, Sangro B, Yau T, Crocenzi TS, Kudo M, Hsu C, et al. Nivolumab in Patients With Advanced Hepatocellular Carcinoma (CheckMate 040): An Open-Label, Non-Comparative, Phase 1/2 Dose Escalation and Expansion Trial. Lancet (2017) 389:2492-502. doi: 10.1016/S0140-6736(17)31046-2

5. Larkin J, Minor D, D’Angelo S, Neyns B, Smylie M, Miller WHJr., et al. Overall Survival in Patients With Advanced Melanoma Who Received Nivolumab Versus Investigator's Choice Chemotherapy in CheckMate 037: A Randomized, Controlled, Open-Label Phase III Trial. J Clin Oncol (2018) 36:383-90. doi: 10.1200/JCO.2016.71.8023

6. Le DT, Uram JN, Wang H, Bartlett BR, Kemberling H, Eyring AD, et al. PD1 Blockade in Tumors With Mismatch-Repair Deficiency. N Engl J Med (2015) 372:2509-20. doi: 10.1056/NEJMoa1500596a

7. O’Neil BH, Wallmark JM, Lorente D, Elez E, Raimbourg J, Gomez-Roca C, et al. Safety and Antitumor Activity of the Anti-PD-1 Antibody Pembrolizumab in Patients With Advanced Colorectal Carcinoma. PloS One (2017) 12:e0189848. doi: 10.1371/journal.pone.0189848

8. Popovic A, Jaffee EM, Zaidi N. Emerging Strategies for Combination Checkpoint Modulators in Cancer Immunotherapy. J Clin Invest (2018) 128:3209-18. doi: 10.1172/JCI120775

9. Das M, Zhu C, Kuchroo VK. Tim-3 and its Role in Regulating Anti-Tumor Immunity. Immunol Rev (2017) 276:97-111. doi: 10.1111/imr.12520

10. Andrews LP, Marciscano AE, Drake CG, Vignali DAA. LAG3 (CD223) as a Cancer Immunotherapy Target. Immunol Rev (2017) 276:80-96. doi: 10.1111/imr.12519

11. Zhao Y, Yang W, Huang Y, Cui R, Li X, Li B. Evolving Roles for Targeting CTLA-4 in Cancer Immunotherapy. Cell Physiol Biochem (2018) 47:721-34. doi: $10.1159 / 000490025$

12. Chauvin J-M, Zarour HM. TIGIT in Cancer Immunotherapy. J Immunother Cancer (2020) 8:e000957. doi: 10.1136/jitc-2020-000957

13. Larkin J, Chiarion-Sileni V, Gonzalez R, Grob JJ, Cowey CL, Lao CD, et al. Combined Nivolumab and Ipilimumab or Monotherapy in Untreated Melanoma. N Engl J Med (2015) 373:23-34. doi: 10.1056/ NEJMoa 1504030

14. Hellmann MD, Paz-Ares L, Bernabe Caro R, Zurawski B, Kim S-W, Carcereny Costa E, et al. Nivolumab Plus Ipilimumab in Advanced NonSmall-Cell Lung Cancer. N Engl J Med (2019) 381:2020-31. doi: 10.1056/ NEJMoa1910231

15. Yau T, Kang Y-K, Kim T-Y, El-Khoueiry AB, Santoro A, Sangro B, et al. Efficacy and Safety of Nivolumab Plus Ipilimumab in Patients With Advanced Hepatocellular Carcinoma Previously Treated With Sorafenib: The CheckMate 040 Randomized Clinical Trial. JAMA Oncol (2020) 6: e204564-e64. doi: 10.1001/jamaoncol.2020.4564

\section{FUNDING}

This study was supported by the China Scholarship Council which provided a PhD fellowship grant to ZG (number 201606230253).

\section{ACKNOWLEDGMENTS}

All figures in this review were created with BioRender.com.

16. De Velasco G, Je Y, Bossé D, Awad MM, Ott PA, Moreira RB, et al. Comprehensive Meta-Analysis of Key Immune-Related Adverse Events From CTLA-4 and PD-1/PD-L1 Inhibitors in Cancer Patients. Cancer Immunol Res (2017) 5:312-18. doi: 10.1158/2326-6066.CIR-16-0237

17. Levin SD, Taft DW, Brandt CS, Bucher C, Howard ED, Chadwick EM, et al. Vstm3 Is a Member of the CD28 Family and an Important Modulator of TCell Function. Eur J Immunol (2011) 41:902-15. doi: 10.1002/eji.201041136

18. Joller N, Hafler JP, Brynedal B, Kassam N, Spoerl S, Levin SD, et al. Cutting Edge: TIGIT has T Cell-Intrinsic Inhibitory Functions. J Immunol (2011) 186:1338-42. doi: 10.4049/jimmunol.1003081

19. Khattri R, Auger JA, Griffin MD, Sharpe AH, Bluestone JA. Lymphoproliferative Disorder in CTLA-4 Knockout Mice Is Characterized by CD28-Regulated Activation of Th2 Responses. J Immunol (1999) 162:5784-91.

20. Boles KS, Vermi W, Facchetti F, Fuchs A, Wilson TJ, Diacovo TG, et al. A Novel Molecular Interaction for the Adhesion of Follicular CD4 T Cells to Follicular DC. Eur J Immunol (2009) 39:695-703. doi: 10.1002/eji.200839116

21. Yu X, Harden K, Gonzalez LC, Francesco M, Chiang E, Irving B, et al. The Surface Protein TIGIT Suppresses T Cell Activation by Promoting the Generation of Mature Immunoregulatory Dendritic Cells. Nat Immunol (2009) 10:48-57. doi: 10.1038/ni.1674

22. Stanietsky N, Simic H, Arapovic J, Toporik A, Levy O, Novik A, et al. The Interaction of TIGIT With PVR and PVRL2 Inhibits Human NK Cell Cytotoxicity. Proc Natl Acad Sci U S A (2009) 106:17858-63. doi: 10.1073/ pnas.0903474106

23. Liu S, Zhang H, Li M, Hu D, Li C, Ge B, et al. Recruitment of Grb2 and SHIP1 by the ITT-Like Motif of TIGIT Suppresses Granule Polarization and Cytotoxicity of NK Cells. Cell Death Differ (2013) 20:456-64. doi: 10.1038/ cdd.2012.141

24. Li M, Xia P, Du Y, Liu S, Huang G, Chen J, et al. T-Cell Immunoglobulin and ITIM Domain (TIGIT) Receptor/Poliovirus Receptor (PVR) Ligand Engagement Suppresses Interferon- $\gamma$ Production of Natural Killer Cells Via $\beta$-Arrestin 2-Mediated Negative Signaling*. J Biol Chem (2014) 289:17647-57. doi: 10.1074/jbc.M114.572420

25. Reches A, Ophir Y, Stein N, Kol I, Isaacson B, Charpak Amikam Y, et al. Nectin4 Is a Novel TIGIT Ligand Which Combines Checkpoint Inhibition and Tumor Specificity. J Immunother Cancer (2020) 8(1):e000266. doi: 10.1136/jitc-2019-000266

26. Masson D, Jarry A, Baury B, Blanchardie P, Laboisse C, Lustenberger P, et al. Overexpression of the CD155 Gene in Human Colorectal Carcinoma. Gut (2001) 49:236-40. doi: 10.1136/gut.49.2.236

27. Nakai R, Maniwa Y, Tanaka Y, Nishio W, Yoshimura M, Okita Y, et al Overexpression of Necl-5 Correlates With Unfavorable Prognosis in Patients With Lung Adenocarcinoma. Cancer Sci (2010) 101:1326-30. doi: 10.1111/ j.1349-7006.2010.01530.x

28. Bevelacqua V, Bevelacqua Y, Candido S, Skarmoutsou E, Amoroso A, Guarneri C, et al. Nectin Like-5 Overexpression Correlates With the Malignant Phenotype in Cutaneous Melanoma. Oncotarget (2012) 3:88292. doi: 10.18632 /oncotarget.594

29. Nishiwada S, Sho M, Yasuda S, Shimada K, Yamato I, Akahori T, et al. Clinical Significance of CD155 Expression in Human Pancreatic Cancer. Anticancer Res (2015) 35:2287-97.

30. Sloan KE, Eustace BK, Stewart JK, Zehetmeier C, Torella C, Simeone M, et al. CD155/PVR Plays a Key Role in Cell Motility During Tumor Cell Invasion and Migration. BMC Cancer (2004) 4:73. doi: 10.1186/1471-2407-4-73 
31. Ge Z, Zhou G, Carrascosa LC, Gausvik E, Boor PPC, Noordam L, et al. TIGIT and PD1 Co-Blockade Restores Ex Vivo Functions of Human TumorInfiltrating CD8+ T Cells in Hepatocellular Carcinoma. Cell Mol Gastroenterol Hepatol (2021) 12(2):443-64. doi: 10.1016/j.jcmgh.2021. 03.003

32. Lange R, Peng X, Wimmer E, Lipp M, Bernhardt G. The Poliovirus Receptor CD155 Mediates Cell-to-Matrix Contacts by Specifically Binding to Vitronectin. Virology (2001) 285:218-27. doi: 10.1006/viro.2001.0943

33. Takai Y, Irie K, Shimizu K, Sakisaka T, Ikeda W. Nectins and Nectin-Like Molecules: Roles in Cell Adhesion, Migration, and Polarization. Cancer Sci (2003) 94:655-67. doi: 10.1111/j.1349-7006.2003.tb01499.x

34. He Y, Bowman VD, Mueller S, Bator CM, Bella J, Peng X, et al. Interaction of the Poliovirus Receptor With Poliovirus. Proc Natl Acad Sci (2000) 97:79. doi: 10.1073/pnas.97.1.79

35. Li X-Y, Das I, Lepletier A, Addala V, Bald T, Stannard K, et al. CD155 Loss Enhances Tumor Suppression Via Combined Host and Tumor-Intrinsic Mechanisms. J Clin Invest (2018) 128:2613-25. doi: 10.1172/JCI98769

36. Lepletier A, Madore J, O’Donnell JS, Johnston RL, Li X-Y, McDonald E, et al. Tumor CD155 Expression Is Associated With Resistance to Anti-PD1 Immunotherapy in Metastatic Melanoma. Clin Cancer Res (2020) 26 (14):3671-81. doi: 10.1158/1078-0432.CCR-19-3925

37. Chiu DK-C, Yuen VW-H, Cheu JW-S, Wei LL, Ting V, Fehlings M, et al. Hepatocellular Carcinoma Cells Upregulate PVRL1, Stabilizing PVR and Inhibiting the Cytotoxic T-Cell Response Via TIGIT to Mediate Tumor Resistance to PD1 Inhibitors in Mice. Gastroenterology (2020) 159(2):60923. doi: 10.1053 /j.gastro.2020.03.074

38. Braun M, Aguilera AR, Sundarrajan A, Corvino D, Stannard K, Krumeich S, et al. CD155 on Tumor Cells Drives Resistance to Immunotherapy by Inducing the Degradation of the Activating Receptor CD226 in CD8(+) T Cells. Immunity (2020) 53:805-23.e15. doi: 10.1016/j.immuni.2020. 09.010a

39. Pende D, Castriconi R, Romagnani P, Spaggiari GM, Marcenaro S, Dondero A, et al. Expression of the DNAM-1 Ligands, Nectin-2 (CD112) and Poliovirus Receptor (CD155), on Dendritic Cells: Relevance for Natural Killer-Dendritic Cell Interaction. Blood (2006) 107:2030-36. doi: 10.1182/ blood-2005-07-2696

40. Sanchez-Correa B, Gayoso I, Bergua JM, Casado JG, Morgado S, Solana R, et al. Decreased Expression of DNAM-1 on NK Cells From Acute Myeloid Leukemia Patients. Immunol Cell Biol (2012) 90:109-15. doi: 10.1038/ icb. 2011.15

41. El-Sherbiny YM, Meade JL, Holmes TD, McGonagle D, Mackie SL, Morgan AW, et al. The Requirement for DNAM-1, NKG2D, and NKp46 in the Natural Killer Cell-Mediated Killing of Myeloma Cells. Cancer Res (2007) 67:8444-9. doi: 10.1158/0008-5472.CAN-06-4230

42. Lozano E, Mena MP, Díaz T, Martin-Antonio B, León S, Rodríguez-Lobato LG, et al. Nectin-2 Expression on Malignant Plasma Cells Is Associated With Better Response to TIGIT Blockade in Multiple Myeloma. Clin Cancer Res (2020) 26:4688-98. doi: 10.1158/1078-0432.CCR-19-3673

43. Guillerey C, Harjunpää H, Carrié N, Kassem S, Teo T, Miles K, et al. TIGIT Immune Checkpoint Blockade Restores CD8(+) T-Cell Immunity Against Multiple Myeloma. Blood (2018) 132:1689-94. doi: 10.1182/blood-2018-01825265

44. Casado JG, Pawelec G, Morgado S, Sanchez-Correa B, Delgado E, Gayoso I, et al. Expression of Adhesion Molecules and Ligands for Activating and Costimulatory Receptors Involved in Cell-Mediated Cytotoxicity in a Large Panel of Human Melanoma Cell Lines. Cancer Immunol Immunother (2009) 58:1517-26. doi: 10.1007/s00262-009-0682-y

45. Miao X, Yang ZL, Xiong L, Zou Q, Yuan Y, Li J, et al. Nectin-2 and DDX3 are Biomarkers for Metastasis and Poor Prognosis of Squamous Cell/ Adenosquamous Carcinomas and Adenocarcinoma of Gallbladder. Int $J$ Clin Exp Pathol (2013) 6:179-90. doi: 10.3109/07357907.2012.756113

46. Zhu Y, Paniccia A, Schulick AC, Chen W, Koenig MR, Byers JT, et al. Identification of CD112R as a Novel Checkpoint for Human T Cells. J Exp Med (2016) 213:167-76. doi: 10.1084/jem.20150785

47. Murter B, Pan X, Ophir E, Alteber Z, Azulay M, Sen R, et al. Mouse PVRIG Has CD8(+) T Cell-Specific Coinhibitory Functions and Dampens Antitumor Immunity. Cancer Immunol Res (2019) 7:244-56. doi: 10.1158/ 2326-6066.CIR-18-0460
48. Whelan S, Ophir E, Kotturi MF, Levy O, Ganguly S, Leung L, et al. PVRIG and PVRL2 Are Induced in Cancer and Inhibit CD8(+) T-Cell Function. Cancer Immunol Res (2019) 7:257-68. doi: 10.1158/2326-6066.CIR-18-0442

49. Parry RV, Chemnitz JM, Frauwirth KA, Lanfranco AR, Braunstein I, Kobayashi SV, et al. CTLA-4 and PD-1 Receptors Inhibit T-Cell Activation by Distinct Mechanisms. Mol Cell Biol (2005) 25:9543. doi: 10.1128/MCB.25.21.9543-9553.2005

50. Josefsson SE, Huse K, Kolstad A, Beiske K, Pende D, Steen CB, et al. T Cells Expressing Checkpoint Receptor TIGIT Are Enriched in Follicular Lymphoma Tumors and Characterized by Reversible Suppression of TCell Receptor Signaling. Clin Cancer Res (2018) 24:870-81. doi: 10.1158/ 1078-0432.CCR-17-2337

51. Lozano E, Dominguez-Villar M, Kuchroo V, Hafler DA. The TIGIT/CD226 Axis Regulates Human T Cell Function. J Immunol (2012) 188:3869-75. doi: 10.4049/jimmunol.1103627

52. Johnston RJ, Comps-Agrar L, Hackney J, Yu X, Huseni M, Yang Y, et al. The Immunoreceptor TIGIT Regulates Antitumor and Antiviral CD8(+) T Cell Effector Function. Cancer Cell (2014) 26:923-37. doi: 10.1016/ j.ccell.2014.10.018

53. Pauken KE, Wherry EJ. TIGIT and CD226: Tipping the Balance Between Costimulatory and Coinhibitory Molecules to Augment the Cancer Immunotherapy Toolkit. Cancer Cell (2014) 26:785-87. doi: 10.1016/ j.ccell.2014.11.016

54. Chauvin JM, Pagliano O, Fourcade J, Sun Z, Wang H, Sander C, et al. TIGIT and PD-1 Impair Tumor Antigen-Specific CD8(+) T Cells in Melanoma Patients. J Clin Invest (2015) 125:2046-58. doi: 10.1172/JCI80445

55. Inozume $\mathrm{T}$, Yaguchi $\mathrm{T}$, Furuta J, Harada $\mathrm{K}$, Kawakami $\mathrm{Y}$, Shimada $\mathrm{S}$. Melanoma Cells Control Antimelanoma CTL Responses Via Interaction Between TIGIT and CD155 in the Effector Phase. J Invest Dermatol (2016) 136:255-63. doi: 10.1038/JID.2015.404

56. Hu F, Wang W, Fang C, Bai C. TIGIT Presents Earlier Expression Dynamic Than PD-1 in Activated CD8+ T Cells and Is Upregulated in Non-Small Cell Lung Cancer Patients. Exp Cell Res (2020) 396:112260. doi: 10.1016/ j.yexcr.2020.112260

57. Thommen DS, Koelzer VH, Herzig P, Roller A, Trefny M, Dimeloe S, et al. A Transcriptionally and Functionally Distinct PD-1+ CD8+ T Cell Pool With Predictive Potential in Non-Small-Cell Lung Cancer Treated With PD-1 Blockade. Nat Med (2018) 24:994-1004. doi: 10.1038/s41591-018-0057-z

58. Ostroumov D, Duong S, Wingerath J, Woller N, Manns MP, Timrott K, et al. Transcriptome Profiling Identifies TIGIT as a Marker of T Cell Exhaustion in Liver Cancer. Hepatology (2021) 73(4):1399-418. doi: 10.1002/hep.31466

59. Xu D, Zhao E, Zhu C, Zhao W, Wang C, Zhang Z, et al. TIGIT and PD-1 may Serve as Potential Prognostic Biomarkers for Gastric Cancer. Immunobiology (2020) 225:151915. doi: 10.1016/j.imbio.2020.151915

60. Lucca LE, Lerner BA, Park C, DeBartolo D, Harnett B, Kumar VP, et al. Differential Expression of the T-Cell Inhibitor TIGIT in Glioblastoma and MS. Neurol Neuroimmunol Neuroinflamm (2020) 7(3):e712. doi: 10.1212/ NXI.0000000000000712

61. Yang ZZ, Kim HJ, Wu H, Jalali S, Tang X, Krull J, et al. TIGIT Expression Is Associated With T-Cell Suppression and Exhaustion and Predicts Clinical Outcome and Anti-PD-1 Response in Follicular Lymphoma. Clin Cancer Res (2020) 26(19):5217-31. doi: 10.1158/1078-0432.CCR-20-0558

62. Kong Y, Zhu L, Schell TD, Zhang J, Claxton DF, Ehmann WC, et al. T-Cell Immunoglobulin and ITIM Domain (TIGIT) Associates With CD8+ T-Cell Exhaustion and Poor Clinical Outcome in AML Patients. Clin Cancer Res (2016) 22:3057-66. doi: 10.1158/1078-0432.CCR-15-2626

63. Liu X, Li M, Wang X, Dang Z, Jiang Y, Wang X, et al. PD-1+ TIGIT+ CD8+ T Cells Are Associated With Pathogenesis and Progression of Patients With Hepatitis B Virus-Related Hepatocellular Carcinoma. Cancer Immunol Immunother (2019) 68:2041-54. doi: 10.1007/s00262-019-02426-5

64. Hung AL, Maxwell R, Theodros D, Belcaid Z, Mathios D, Luksik AS, et al. TIGIT and PD-1 Dual Checkpoint Blockade Enhances Antitumor Immunity and Survival in GBM. Oncoimmunology (2018) 7:e1466769. doi: 10.1080/ 2162402X.2018.1466769

65. Josefsson SE, Beiske K, Blaker YN, Førsund MS, Holte H, Østenstad B, et al. TIGIT and PD-1 Mark Intratumoral T Cells With Reduced Effector Function in B-Cell Non-Hodgkin Lymphoma. Cancer Immunol Res (2019) 7:355-62. doi: 10.1158/2326-6066.CIR-18-0351 
66. Wu L, Mao L, Liu J-F, Chen L, Yu G-T, Yang L-L, et al. Blockade of TIGIT/ CD155 Signaling Reverses T-Cell Exhaustion and Enhances Antitumor Capability in Head and Neck Squamous Cell Carcinoma. Cancer Immunol Res (2019) 7:1700-13. doi: 10.1158/2326-6066.CIR-18-0725

67. Kurtulus S, Sakuishi K, Ngiow SF, Joller N, Tan DJ, Teng MW, et al. TIGIT Predominantly Regulates the Immune Response Via Regulatory T Cells. J Clin Invest (2015) 125:4053-62. doi: 10.1172/JCI81187

68. Ma J, Zheng B, Goswami S, Meng L, Zhang D, Cao C, et al. PD1(Hi) CD8(+) T Cells Correlate With Exhausted Signature and Poor Clinical Outcome in Hepatocellular Carcinoma. J Immunother Cancer (2019) 7:331. doi: 10.1186/ s40425-019-0814-7

69. Dixon KO, Schorer M, Nevin J, Etminan Y, Amoozgar Z, Kondo T, et al. Functional Anti-TIGIT Antibodies Regulate Development of Autoimmunity and Antitumor Immunity. J Immunol (2018) 200:3000-07. doi: 10.4049/ jimmunol.1700407

70. Wang B, Zhang W, Jankovic V, Golubov J, Poon P, Oswald EM, et al. Combination Cancer Immunotherapy Targeting PD-1 and GITR can Rescue CD8+ T Cell Dysfunction and Maintain Memory Phenotype. Sci Immunol (2018) 3(29):eaat7061. doi: 10.1126/sciimmunol.aat7061

71. Jin HS, Ko M, Choi DS, Kim JH, Lee DH, Kang SH, et al. CD226(hi)CD8(+) T Cells Are a Prerequisite for Anti-TIGIT Immunotherapy. Cancer Immunol Res (2020) 8:912-25. doi: 10.1158/2326-6066.CIR-19-0877

72. Weulersse M, Asrir A, Pichler AC, Lemaitre L, Braun M, Carrié N, et al. Eomes-Dependent Loss of the Co-Activating Receptor CD226 Restrains CD8(+) T Cell Anti-Tumor Functions and Limits the Efficacy of Cancer Immunotherapy. Immunity (2020) 53:824-39.e10. doi: 10.1016/j.immuni. 2020.09 .006

73. Gros A, Robbins PF, Yao X, Li YF, Turcotte S, Tran E, et al. PD-1 Identifies the Patient-Specific CD8+ Tumor-Reactive Repertoire Infiltrating Human Tumors. J Clin Invest (2014) 124:2246-59. doi: 10.1172/JCI73639

74. Joller N, Lozano E, Burkett PR, Patel B, Xiao S, Zhu C, et al. Treg Cells Expressing the Coinhibitory Molecule TIGIT Selectively Inhibit Proinflammatory Th1 and Th17 Cell Responses. Immunity (2014) 40:56981. doi: 10.1016/j.immuni.2014.02.012

75. Fuhrman CA, Yeh W-I, Seay HR, Lakshmi PS, Chopra G, Zhang L, et al. Divergent Phenotypes of Human Regulatory T Cells Expressing the Receptors TIGIT and CD226. J Immunol (2015) 195:145-55. doi: 10.4049/ jimmunol.1402381

76. Fourcade J, Sun Z, Chauvin J-M, Ka M, Davar D, Pagliano O, et al. CD226 Opposes TIGIT to Disrupt Tregs in Melanoma. JCI Insight (2018) 3(14): e121157. doi: 10.1172/jci.insight.121157

77. Tan MC, Goedegebuure PS, Belt BA, Flaherty B, Sankpal N, Gillanders WE, et al. Disruption of CCR5-Dependent Homing of Regulatory T Cells Inhibits Tumor Growth in a Murine Model of Pancreatic Cancer. J Immunol (2009) 182:1746-55. doi: 10.4049/jimmunol.182.3.1746

78. Iellem A, Mariani M, Lang R, Recalde H, Panina-Bordignon P, Sinigaglia F, et al. Unique Chemotactic Response Profile and Specific Expression of Chemokine Receptors CCR4 and CCR8 by CD4(+)CD25(+) Regulatory T Cells. J Exp Med (2001) 194:847-53. doi: 10.1084/jem.194.6.847

79. De Simone M, Arrigoni A, Rossetti G, Gruarin P, Ranzani V, Politano C, et al. Transcriptional Landscape of Human Tissue Lymphocytes Unveils Uniqueness of Tumor-Infiltrating T Regulatory Cells. Immunity (2016) 45:1135-47. doi: 10.1016/j.immuni.2016.10.021

80. Tan CL, Kuchroo JR, Sage PT, Liang D, Francisco LM, Buck J, et al. PD-1 Restraint of Regulatory T Cell Suppressive Activity Is Critical for Immune Tolerance. J Exp Med (2021) 218(1):e20182232. doi: 10.1084/ jem.20182232

81. Franceschini D, Paroli M, Francavilla V, Videtta M, Morrone S, Labbadia G, et al. PD-L1 Negatively Regulates CD4+CD25+Foxp3+ Tregs by Limiting STAT-5 Phosphorylation in Patients Chronically Infected With HCV. J Clin Invest (2009) 119:551-64. doi: 10.1172/JCI36604

82. Kumagai S, Togashi Y, Kamada T, Sugiyama E, Nishinakamura H, Takeuchi Y, et al. The PD-1 Expression Balance Between Effector and Regulatory T Cells Predicts the Clinical Efficacy of PD-1 Blockade Therapies. Nat Immunol (2020) 21:1346-58. doi: 10.1038/s41590-020-0769-3

83. Park HJ, Park JS, Jeong YH, Son J, Ban YH, Lee BH, et al. PD-1 Upregulated on Regulatory $\mathrm{T}$ Cells During Chronic Virus Infection Enhances the Suppression of CD8+ T Cell Immune Response Via the Interaction With
PD-L1 Expressed on CD8+ T Cells. J Immunol (2015) 194:5801-11. doi: 10.4049/jimmunol.1401936

84. Hung K, Hayashi R, Lafond-Walker A, Lowenstein C, Pardoll D, Levitsky H. The Central Role of CD4(+) T Cells in the Antitumor Immune Response. J Exp Med (1998) 188:2357-68. doi: 10.1084/jem.188.12.2357

85. Miller JS, Lanier LL. Natural Killer Cells in Cancer Immunotherapy. Annu Rev Cancer Biol (2019) 3:77-103. doi: 10.1146/annurev-cancerbio-030518-055653

86. Souza-Fonseca-Guimaraes F, Cursons J, Huntington ND. The Emergence of Natural Killer Cells as a Major Target in Cancer Immunotherapy. Trends Immunol (2019) 40:142-58. doi: 10.1016/j.it.2018.12.003

87. Zaretsky JM, Garcia-Diaz A, Shin DS, Escuin-Ordinas H, Hugo W, HuLieskovan S, et al. Mutations Associated With Acquired Resistance to PD-1 Blockade in Melanoma. N Engl J Med (2016) 375:819-29. doi: 10.1056/ NEJMoa1604958

88. Gettinger S, Choi J, Hastings K, Truini A, Datar I, Sowell R, et al. Impaired HLA Class I Antigen Processing and Presentation as a Mechanism of Acquired Resistance to Immune Checkpoint Inhibitors in Lung Cancer. Cancer Discov (2017) 7:1420. doi: 10.1158/2159-8290.CD-17-0593

89. Torrejon DY, Abril-Rodriguez G, Champhekar AS, Tsoi J, Campbell KM, Kalbasi A, et al. Overcoming Genetically Based Resistance Mechanisms to PD-1 Blockade. Cancer Discov (2020) 10:1140. doi: 10.1158/2159-8290.CD19-1409

90. Böttcher JP, Bonavita E, Chakravarty P, Blees H, Cabeza-Cabrerizo M, Sammicheli S, et al. NK Cells Stimulate Recruitment of cDC1 Into the Tumor Microenvironment Promoting Cancer Immune Control. Cell (2018) 172:1022-37 e14. doi: 10.1016/j.cell.2018.01.004

91. Pallmer K, Oxenius A. Recognition and Regulation of T Cells by NK Cells. Front Immunol (2016) 7:251. doi: 10.3389/fimmu.2016.00251

92. Schuster IS, Coudert JD, Andoniou CE, Degli-Esposti MA. "Natural Regulators": NK Cells as Modulators of T Cell Immunity. Front Immunol (2016) 7:235-35. doi: 10.3389/fimmu.2016.00235

93. Mocikat R, Braumüller H, Gumy A, Egeter O, Ziegler H, Reusch U, et al. Natural Killer Cells Activated by MHC Class I(low) Targets Prime Dendritic Cells to Induce Protective CD8 T Cell Responses. Immunity (2003) 19:5619. doi: 10.1016/S1074-7613(03)00264-4

94. Zhang Q, Bi J, Zheng X, Chen Y, Wang H, Wu W, et al. Blockade of the Checkpoint Receptor TIGIT Prevents NK Cell Exhaustion and Elicits Potent Anti-Tumor Immunity. Nat Immunol (2018) 19:723-32. doi: 10.1038/ s41590-018-0132-0

95. Long EO, Kim HS, Liu D, Peterson ME, Rajagopalan S. Controlling Natural Killer Cell Responses: Integration of Signals for Activation and Inhibition. Annu Rev Immunol (2013) 31:227-58. doi: 10.1146/annurev-immunol020711-075005

96. Sanchez-Correa B, Valhondo I, Hassouneh F, Lopez-Sejas N, Pera A, Bergua JM, et al. DNAM-1 and the TIGIT/PVRIG/TACTILE Axis: Novel Immune Checkpoints for Natural Killer Cell-Based Cancer Immunotherapy. Cancers (Basel) (2019) 11(6):877. doi: 10.3390/cancers11060877

97. Carlsten M, Norell H, Bryceson YT, Poschke I, Schedvins K, Ljunggren HG, et al. Primary Human Tumor Cells Expressing CD155 Impair Tumor Targeting by Down-Regulating DNAM-1 on NK Cells. J Immunol (2009) 183:4921-30. doi: 10.4049/jimmunol.0901226

98. Chauvin JM, Ka M, Pagliano O, Menna C, Ding Q, DeBlasio R, et al. IL15 Stimulation With TIGIT Blockade Reverses CD155-Mediated NK-Cell Dysfunction in Melanoma. Clin Cancer Res (2020) 26:5520-33. doi: 10.1158/1078-0432.CCR-20-0575

99. Wang F, Hou H, Wu S, Tang Q, Liu W, Huang M, et al. TIGIT Expression Levels on Human NK Cells Correlate With Functional Heterogeneity Among Healthy Individuals. Eur J Immunol (2015) 45:2886-97. doi: 10.1002/eji.201545480

100. Maas RJ, Hoogstad-van Evert JS, van der Meer JM, Mekers V, Rezaeifard S, Korman AJ, et al. TIGIT Blockade Enhances Functionality of Peritoneal NK Cells With Altered Expression of DNAM-1/TIGIT/CD96 Checkpoint Molecules in Ovarian Cancer. Oncoimmunology (2020) 9:1843247. doi: 10.1080/2162402X.2020.1843247

101. Sun H, Huang Q, Huang M, Wen H, Lin R, Zheng M, et al. Human CD96 Correlates to Natural Killer Cell Exhaustion and Predicts the Prognosis of Human Hepatocellular Carcinoma. Hepatology (2019) 70:168-83. doi: 10.1002/hep.30347 
102. Gur C, Ibrahim Y, Isaacson B, Yamin R, Abed J, Gamliel M, et al. Binding of the Fap2 Protein of Fusobacterium Nucleatum to Human Inhibitory Receptor TIGIT Protects Tumors From Immune Cell Attack. Immunity (2015) 42:344-55. doi: 10.1016/j.immuni.2015.01.010

103. Ahn M, Niu J, Kim D, Rasco D, Mileham K, Chung H, et al. 1400P Vibostolimab, an Anti-TIGIT Antibody, as Monotherapy and in Combination With Pembrolizumab in Anti-PD-1/PD-L1-Refractory NSCLC. Ann Oncol (2020) 31:S887. doi: 10.1016/j.annonc.2020.08.1714

104. Niu J, Nagrial A, Voskoboynik M, Chung H, Lee D, Ahn M, et al. 1410P Safety and Efficacy of Vibostolimab, an Anti-TIGIT Antibody, Plus Pembrolizumab in Patients With Anti-PD-1/PD-L1-Naive NSCLC. Ann Oncol (2020) 31:S891-S92. doi: 10.1016/j.annonc.2020.08.1724

105. Rodriguez-Abreu D, Johnson ML, Hussein MA, Cobo M, Patel AJ, Secen NM, et al. Primary Analysis of a Randomized, Double-Blind, Phase II Study of the Anti-TIGIT Antibody Tiragolumab (Tira) Plus Atezolizumab (Atezo)
Versus Placebo Plus Atezo as First-Line (1L) Treatment in Patients With PD-L1-Selected NSCLC (CITYSCAPE). J Clin Oncol (2020) 38:9503-03. doi: 10.1200/JCO.2020.38.15_suppl.9503

Conflict of Interest: The authors declare that the research was conducted in the absence of any commercial or financial relationships that could be construed as a potential conflict of interest.

Copyright (C) 2021 Ge, Peppelenbosch, Sprengers and Kwekkeboom. This is an openaccess article distributed under the terms of the Creative Commons Attribution License (CC BY). The use, distribution or reproduction in other forums is permitted, provided the original author(s) and the copyright owner(s) are credited and that the original publication in this journal is cited, in accordance with accepted academic practice. No use, distribution or reproduction is permitted which does not comply with these terms. 